\title{
Extramitochondrial $\mathrm{Ca}^{2+}$ in the Nanomolar Range Regulates Glutamate-Dependent Oxidative Phosphorylation on Demand
}

\author{
Frank Norbert Gellerich ${ }^{1}$, Zemfira Gizatullina ${ }^{2}$, Odeta Arandarcikaite ${ }^{3}$, Doreen Jerzembek ${ }^{1}$, Stefan \\ Vielhaber $^{2}$, Enn Seppet ${ }^{4}$, Frank Striggow ${ }^{1}$
}

1 KeyNeurotek Pharmaceuticals AG, ZENIT Technology Park, Magdeburg, Germany, 2 Department of Neurology, Otto von Guericke University Magdeburg, Magdeburg, Germany, $\mathbf{3}$ Institute for Biomedical Research, Kaunas University of Medicine, Kaunas, Lithuania, 4 Department of Pathophysiology, Centre of Molecular and Clinical Medicine, University of Tartu, Tartu, Estonia

\begin{abstract}
We present unexpected and novel results revealing that glutamate-dependent oxidative phosphorylation (OXPHOS) of brain mitochondria is exclusively and efficiently activated by extramitochondrial $\mathrm{Ca}^{2+}$ in physiological concentration ranges $\left(\mathrm{S}_{0.5}=360 \mathrm{nM} \mathrm{Ca}^{2+}\right)$. This regulation was not affected by $\mathrm{RR}$, an inhibitor of the mitochondrial $\mathrm{Ca}^{2+}$ uniporter. Active respiration is regulated by glutamate supply to mitochondria via aralar, a mitochondrial glutamate/aspartate carrier with regulatory $\mathrm{Ca}^{2+}$-binding sites in the mitochondrial intermembrane space providing full access to cytosolic $\mathrm{Ca}^{2+}$. At micromolar concentrations, $\mathrm{Ca}^{2+}$ can also enter the intramitochondrial matrix and activate specific dehydrogenases. However, the latter mechanism is less efficient than extramitochondrial $\mathrm{Ca}^{2+}$ regulation of respiration/OXPHOS via aralar. These results imply a new mode of glutamate-dependent OXPHOS regulation as a demand-driven regulation of mitochondrial function. This regulation involves the mitochondrial glutamate/aspartate carrier aralar which controls mitochondrial substrate supply according to the level of extramitochondrial $\mathrm{Ca}^{2+}$.
\end{abstract}

Citation: Gellerich FN, Gizatullina Z, Arandarcikaite O, Jerzembek D, Vielhaber S, et al. (2009) Extramitochondrial Ca ${ }^{2+}$ in the Nanomolar Range Regulates Glutamate-Dependent Oxidative Phosphorylation on Demand. PLoS ONE 4(12): e8181. doi:10.1371/journal.pone.0008181

Editor: Mark R. Cookson, National Institutes of Health, United States of America

Received April 28, 2009; Accepted October 30, 2009; Published December 9, 2009

Copyright: (c) 2009 Gellerich et al. This is an open-access article distributed under the terms of the Creative Commons Attribution License, which permits unrestricted use, distribution, and reproduction in any medium, provided the original author and source are credited.

Funding: This work was supported by the European Huntington network, the DFG (Ge 664/11-2), the German Federal Ministry of Economics and Technology grant No. IWO72052 (MitoscreenTest), Estonian Ministry of Education and Research (SF0180114As08) and Estonian Science Foundation (grants No. 7117 and 7823). The funders had no role in study design, data collection and analysis, decision to publish, or preparation of the manuscript

Competing Interests: Frank Gellerich, Zemfira Gizatullina, Doreen Jerzembeck and Frank Striggow are employees of Keyneurotek Pharmaceuticals AG, a privately held biotechnology company.

* E-mail: frank.gellerich@keyneurotek.de

\section{Introduction}

It has been assumed that ADP formed by ATP-consuming enzymes activates OXPHOS [1]. However, cytosolic ADP of the heart muscle is only insignificantly increased in vivo during elevated work loads [2,3]. Therefore, two hypotheses have been proposed, (i) the dynamic compartmentation of $\mathrm{ADP}$, assuming that necessary ADP augmentations occur exclusively within the mitochondrial intermembrane space $[4,5]$ and (ii) the stimulation of OXPHOS due to $\mathrm{Ca}^{2+}$ influx into the mitochondrial matrix via $\mathrm{Ca}^{2+}$ uniporter, followed by the activation of distinct intramitochondrial dehydrogenases [6,7]. Some authors also assume a $\mathrm{Ca}^{2+}$ stimulation of $\mathrm{F}_{0} \mathrm{~F}_{1}$-ATP synthase $[8,9]$. However, both scenarios comply only partially with the in vivo findings outlined above [10].

Recent data suggest that the activity of the malate aspartate shuttle (MAS), including glutamate/aspartate carriers as aralar, is activated by extramitochondrial $\mathrm{Ca}^{2+}\left(\mathrm{S}_{0.5}=324 \mathrm{nM}\right)$ [11-13]. The N-terminal regulatory $\mathrm{Ca}^{2+}$-binding site of aralar is located within the mitochondrial intermembrane space [11-13] where it can interact with $\mathrm{Ca}^{2+}$ passing through porin pores of the outer membrane. Aralar supplies OXPHOS with glutamate, a key mitochondrial substrate. In this study, we addressed the question whether OXPHOS can be directly activated by extramitochondrial $\mathrm{Ca}^{2+}$ and if so, whether aralar is involved in this regulation.

\section{Results}

First, we investigated the influence of $\mathrm{Ca}^{2+}$ on OXPHOS of isolated rat brain mitochondria in a medium containing $150 \mathrm{nM}$ free $\mathrm{Ca}^{2+}\left(\mathrm{Ca}^{2+}\right.$ free $)$, corresponding to basal levels of cytosolic $\mathrm{Ca}^{2+}$ under physiological conditions [14]. ADP was added so as to fully activate phosphorylation-related respiration (state 3). Using glutamate/malate as substrate, a relatively low state $3_{\text {glu }} / \mathrm{mal}$ was obtained (Fig. 1A,B). However, state $3_{\text {glu } / \text { mal nearly doubled }}$ immediately after a pulse addition of $4.9 \mu \mathrm{M} \mathrm{Ca}^{2+}$ free (Fig. 1A,B). This $\mathrm{Ca}^{2+}$ activation was not limited by the mitochondrial capacity of OXPHOS, but rather was due to its efficacy in metabolizing glutamate, as succinate conspicuously enhanced respiration above the level of state 3 glu/mal . With pyruvate/malate (Fig. 1C), state $3_{\text {pyr } / \text { mal }}$ significantly exceeded state $3_{\text {glu } / \text { mal }}$ (Fig. 1A,B). However, added $\mathrm{Ca}^{2+}$ did not augment state $3_{\mathrm{pyr} / \mathrm{mal}}$, whereas added succinate did (Fig. 1C). Fig. 1D demonstrates that there was also no $\mathrm{Ca}^{2+}$ effect on complex II-dependent state $3_{\text {suc }}$ with succinate/ rotenone. Overall, these results show that $\mathrm{Ca}^{2+}$ activation of OXPHOS in isolated brain mitochondria is a glutamate-specific phenomenon. The next series of experiments revealed that RR, an inhibitor of the mitochondrial $\mathrm{Ca}^{2+}$ uniporter [15], is not able to modulate $\mathrm{Ca}^{2+}$ effects on state 3 with any substrate (Fig. 1B-D). We performed these experiments in the presence of relatively low 


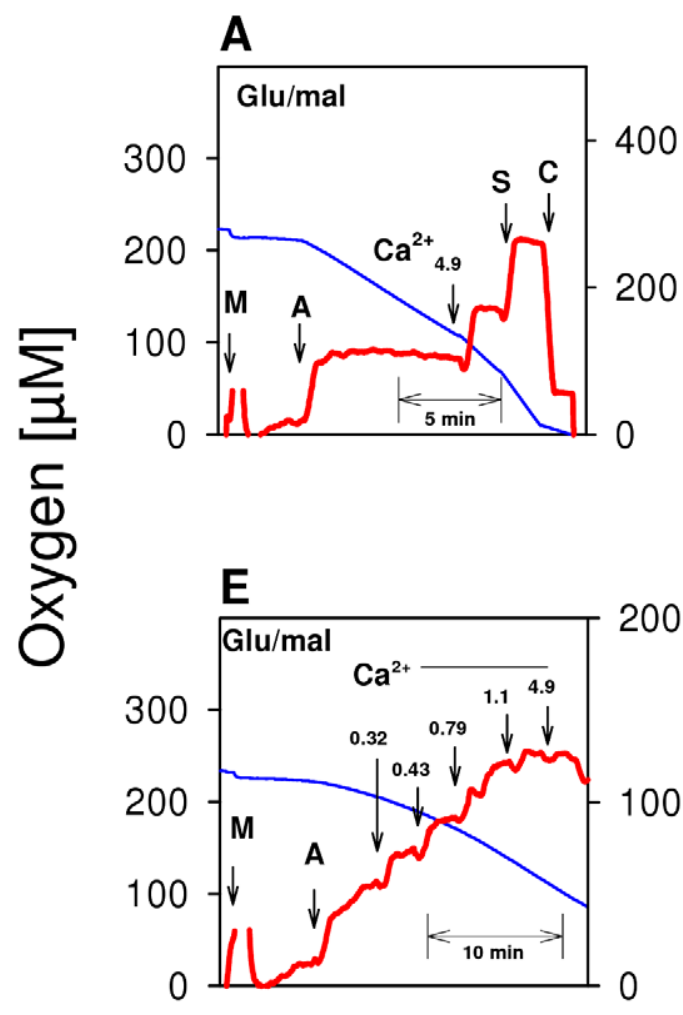

B
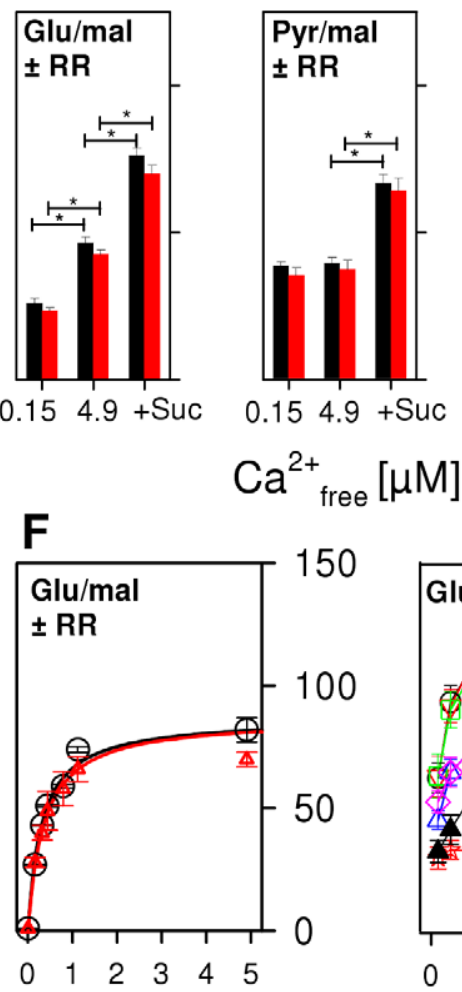
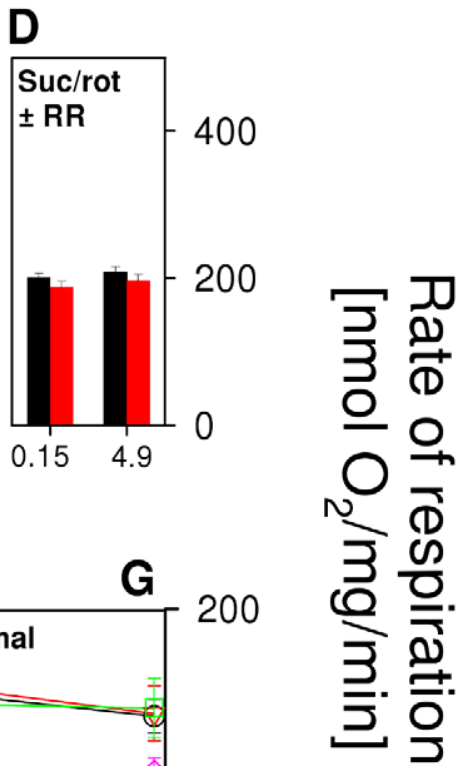

$\mathrm{Ca}^{2+}$ free $[\mu \mathrm{M}]$

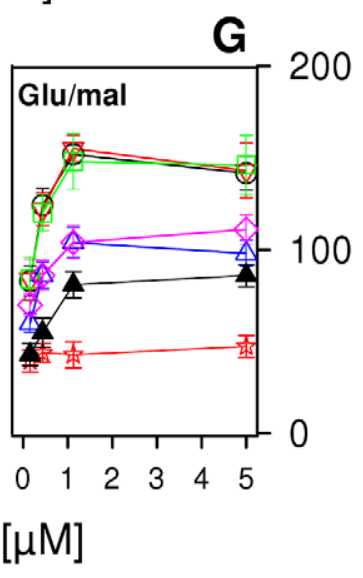

Figure 1. Exclusive activation of glutamate-dependent state 3 respiration of brain mitochondria by extramitochondrial $\mathrm{Ca}^{2+}$ in the nanomolar range. $(A, E)$ Respirograms of rat brain mitochondria were obtained by high-resolution respirometry. (A) Isolated rat brain mitochondria were incubated in EGTA medium $\left(\mathrm{Ca}^{2+}\right.$ free $\left.=0.15 \mu \mathrm{M}\right)$ in the presence of $10 \mathrm{mM}$ glutamate and $2 \mathrm{mM}$ malate as substrates. Additions: $\mathrm{M}, 0.06 \mathrm{mg} / \mathrm{ml}$ brain mitochondria, A, $2.5 \mathrm{mM} \mathrm{ADP}$ to activate the phosphorylation-related respiration (state 3); $\mathrm{Ca}_{4,9}^{2+} 4.9 \mu \mathrm{M} \mathrm{Ca}{ }^{2+}{ }_{\text {freei }} \mathrm{S}, 10 \mathrm{mM}$ succinate as substrate of respiratory chain complex II; C, $5 \mu \mathrm{M}$ carboxyatractyloside to block the adenine nucleotide translocase. Blue lines indicate the oxygen concentration and red lines represent respiration rates $\left(\mathrm{nmol} \mathrm{O}_{2} / \mathrm{mg}\right.$ mitochondrial protein $/ \mathrm{min}$ ). (B) Means of state 3 respiration $\pm \mathrm{S}$.E. as measured in experiments shown in A without (black columns, $n=6$ ) or with $250 \mathrm{nM} \mathrm{RR}$, an inhibitor of mitochondrial $\mathrm{Ca}^{2+}$ uptake (red columns, $n=6$ ). First group of columns, state 3 at $\mathrm{Ca}^{2+}$ free $=0.15 \mu \mathrm{M}$. Second group, state 3 with $\mathrm{Ca}^{2+}$ free $=4.9 \mu \mathrm{M}$. Third group, state 3 with $\mathrm{Ca}^{2+}{ }_{\text {free }}=4.9 \mu \mathrm{M}$ in the additional presence of $10 \mu \mathrm{M}$ succinate. *, $p<0.05$. (C) As $B$, but derived from experiments with $10 \mathrm{mM}$ pyruvate $+2 \mathrm{mM}$ malate as substrates. ${ }^{*}, p<0.05$. (D) As $B$, but derived from experiments with $10 \mathrm{mM}$ succinate $+2 \mu \mathrm{M}$ rotenone as substrate. (E) $\mathrm{Ca}^{2+}$ titration of state $3_{\mathrm{glu} / \mathrm{mal}}$ by stepwise increase of $\mathrm{Ca}^{2+}$ as indicated either without $(E, F)$ or with (F) $250 \mathrm{nM} \mathrm{RR}$. (F) Incremental accretions of $\mathrm{Ca}^{2+}{ }_{\text {-induced state } 3 \mathrm{glu} / \mathrm{mal}}$ were plotted against the fluorimetrically measured $\mathrm{Ca}^{2+}$ activity (Fig. 1F), allowing the calculation of the half-activation constant $\left(\mathrm{S}_{0.5}\right)$ and the maximum velocity $\left(\mathrm{V}_{\max }\right)$ using the SigmaPlot kinetic module as given in the text. (G) Rates of state $3_{\text {glu/mal }}$ respiration obtained by $\mathrm{Ca}^{2+}$ titrations under various conditions. $(O)$ Control mitochondria were investigated as in Fig. 1E. ( $\square)$ As $(\bigcirc)$, but in the additional presence of $10 \%$ dextran 20. $(\nabla)$ As $(\bigcirc)$, but in the additional presence of $1 \mathrm{mM} C s A$. $(\triangle)$ as $(\bigcirc)$, but mitochondria isolated without digitonin were used. $(\diamond)$ as $(\bigcirc)$, but mitoplasts were used. ( $\downarrow$ ) as $(\bigcirc)$, but mitochondria were uncoupled by $50 \mathrm{nM}$ FCCP from the beginning of experiments, and then $\mathrm{Ca}^{2+}$ titration was performed. $(\mathbf{\Lambda})$ as $(\bigcirc)$, but $\mathrm{Ca}^{2+}$ was adjusted at the beginning of experiments as indicated. Thereafter, $100 \mu \mathrm{M}$ ADP was added, causing short transitions between the active and resting states of respiration. After reaching state 4 respiration, FCCP titrations were performed to uncouple respiration and ATP generation. Maximum respiration rates were obtained at 60 or $80 \mathrm{nM} \mathrm{FCCP}$ and were plotted against the $\mathrm{Ca}^{2+}$ free value for the respective incubation. Data are means \pm S.E. of 4 independent experiments.

doi:10.1371/journal.pone.0008181.g001

RR concentrations (250 $\mathrm{nM})$ in order to avoid possible unspecific RR effects. Nevertheless, even in the presence of up to $5 \mu \mathrm{M} R R$, extramitochondrial $\mathrm{Ca}^{2+}$-induced stimulation of state $3_{\text {glu }} /$ mal was detectable (Data not shown).

Next, we investigated the kinetics of $\mathrm{Ca}^{2+}$ activation (Fig. 1E,F). $\mathrm{Ca}^{2+}$ was increased in steps. Increments of $\mathrm{Ca}^{2+}$-induced state $3_{\text {glu/mal }}$ were plotted against fluorimetrically measured $\mathrm{Ca}^{2+}$ (Fig. 1F) in order to determine the half-activation constant $\left(\mathrm{S}_{0.5}\right)$ and the extent of $\mathrm{Ca}^{2+}$ stimulation $\left(\mathrm{S}_{0.5}=356 \pm 39 \mathrm{nM} \mathrm{Ca}^{2+}{ }_{\text {freee }}\right.$, $\left.\mathrm{V}_{\max }=86 \pm 5 \mathrm{nmol} \mathrm{O}_{2} / \mathrm{mg} / \mathrm{min}\right)$. Neither parameter was affected by RR $\left(\mathrm{S}_{0.5}=306 \pm 35 \mathrm{nM} \mathrm{Ca}^{2+}\right.$ free, $\mathrm{V}_{\max }=88 \pm 8 \mathrm{nmol} \mathrm{O} \mathrm{O}_{2} / \mathrm{mg} /$ min). Thus, $\mathrm{Ca}^{2+}$ influx into the mitochondrial matrix appears not to be required for state $3_{\text {glu/mal }}$ stimulation and, hence, $\mathrm{Ca}^{2+}$ activation must be an extramitochondrial effect.
To exclude furthermore artificial $\mathrm{Ca}^{2+}$ effects due to potential interactions of digitonin with mitochondrial membranes, we also varied the digitonin concentration used during the preparation of mitochondria to permeabilize synaptosomal membranes. Omitting digitonin did not cause any significant changes in the extent of extramitochondrial $\mathrm{Ca}^{2+}$ activation of state $3_{\text {glu/mal }}$ (Fig. 1G) compared with control mitochondria prepared with digitonin (Fig. 1G). Thus, digitonin-related artifacts can be excluded. It should be noted that in the absence of digitonin, synaptosomal mitochondria remained inaccessible, and therefore respiratory rates were significantly decreased in digitonin-free experiments (Fig. 1G). On the other hand, large additions of digitonin $(1.2 \mathrm{mg}$ digitonin $/ \mathrm{mg}$ mitochondrial protein) led to a removal of mitochondrial outer membranes and the generation of mitoplasts $[16,17]$. Consequently, 
the accessibility of mitochondrial $\mathrm{Ca}^{2+}$-binding sites, originally located within the inner membrane space, to $\mathrm{Ca}^{2+}$ was facilitated but no changes of $\mathrm{Ca}^{2+}$ activation were detectable (Fig. 1G). As previously observed in heart mitoplasts [17], we also registered lower respiratory rates compared with control mitochondria; this was probably due to unspecific side effects of digitonin on mitoplasts. This finding suggests that $\mathrm{Ca}^{2+}$ diffusion through porin pores of the mitochondrial outer membrane does not limit its interaction with mitochondrial $\mathrm{Ca}^{2+}$-binding sites exposed into the inner membrane space and thus, does not compromise extramitochondrial $\mathrm{Ca}^{2+}$ regulation of glutamate/malate-dependent respiration and $\mathrm{OX}$ PHOS. Another experimental setup was used to obtain support for this interpretation. In intact cells, the colloid osmotic pressure increases the diffusion resistance of the mitochondrial outer membrane against metabolites passing the porin pores [18]. We therefore simulated the intracellular oncotic pressure by addition of $10 \%$ dextran [18], but again observed a similar extramitochondrial $\mathrm{Ca}^{2+}$ stimulation of state 3 glu/mal respiration and OXPHOS (Fig. 1G). Moreover, the addition of $2 \mu \mathrm{M}$ cyclosporine A (CsA), an inhibitor of the mitochondrial permeability pore (PTP)[19], did not affect the extramitochondrial $\mathrm{Ca}^{2+}$ regulation of brain mitochondria (Fig. 1G), suggesting that PTP is not involved in the phenomenon of extramitochondrial $\mathrm{Ca}^{2+}$ regulation of state $3_{\text {glu }} / \mathrm{mal}$ and OXPHOS.

We then investigated the influence of mitochondrial uncoupling on $\mathrm{Ca}^{2+}$ stimulation of OXPHOS. Since aralar is an electrogenic carrier [20], glutamate transport into mitochondria requires a sufficiently high mitochondrial membrane potential. Accordingly, mitochondria uncoupled by $50 \mathrm{nM} \mathrm{FCGP}$ at the beginning of the experiment could not be activated by the following $\mathrm{Ca}^{2+}$ titration, owing to the dissipation of membrane potential (Fig. 1G). In a second approach, different $\mathrm{Ca}^{2+}$ free concentrations were initially adjusted followed by FCCP titration of the nonphosphorylating respiration (state 4). This application scheme resulted in enhanced maximum rates of uncoupled respiration in a $\mathrm{Ca}^{2+}$-dependent manner (Fig. 1G). However, since FCCP also caused an incomplete dissipation of mitochondrial membrane potentials, maximum rates of uncoupled respiration were lower than in control experiments without FCCP (Fig. 1G). Obviously, cytosolic $\mathrm{Ca}^{2+}$ can modulate glutamate transport rate via aralar but is not able to adjust the thermodynamic conditions necessary for glutamate uptake.

Therefore, several lines of experimental evidence clearly support the assumption that extramitochondrial $\mathrm{Ca}^{2+}$ regulation of glutamate-dependent OXPHOS is a physiologically relevant phenomenon, rather than being an experimental artifact.

In intact cells, mitochondria are not exposed to such high ADP concentrations as applied here (Fig. 1). In order to address this issue in more detail, we investigated whether $\mathrm{Ca}^{2+}$ can also stimulate glutamate-dependent respiration at physiological ADP levels and, if so, whether this stimulation by $\mathrm{Ca}^{2+}$ is a reversible phenomenon. These measurements were started in EGTA-free medium $\left(\mathrm{Ca}^{2+}\right.$ free $\sim 0.6 \mu \mathrm{M})$ containing RR. With glutamate/malate as substrates, $\operatorname{ADP}(150 \mu \mathrm{M})$ caused an intermediate activation of phosphorylating respiration with a maximum rate of $50 \mathrm{nmol} \mathrm{O}_{2} / \mathrm{mg} / \mathrm{min}$ (calculated by subtracting state 4 from state 3 respiration; Fig. 2A,B). By the addition of $100 \mu \mathrm{M}$ EGTA, $\mathrm{Ca}^{2+}$ free was then lowered to $\sim 150 \mathrm{nM}$, which was less than half the value of $\mathrm{S}_{0.5}=360 \mathrm{nM}$ for $\mathrm{Ca}^{2+}$ activation of state 3 glu/mal (Fig. 1F). Under these conditions, the rate of ADP-induced respiration was significantly reduced compared to experiments in the presence of higher $\mathrm{Ca}^{2+}$ free levels (Fig. 2A,B). Increasing of $\mathrm{Ca}^{2+}$ free up to $4.9 \mu \mathrm{M}$ again markedly accelerated state $3_{\text {glu } / \mathrm{mal}}$ and OXPHOS, demonstrating perfect reversibility of extramitochondrial $\mathrm{Ca}^{2+}$ regulation. In contrast, similar $\mathrm{Ca}^{2+}$ changes did not affect OXPHOS rates using pyruvate/ malate (Fig. 2C) or succinate/rotenone as substrates (Fig. 2D).

In order to find out whether $250 \mathrm{nM} \mathrm{RR}$ is able to inhibit mitochondrial $\mathrm{Ca}^{2+}$ uptake via $\mathrm{Ca}^{2+}$ uniporter, we performed another experiment using fluorimetric $\mathrm{Ca}^{2+}$ measurements in EGTA-free medium. It is well known that repeated $\mathrm{Ca}^{2+}$ additions lead to a sequential and reversible increase of $\mathrm{Ca}$ Green fluorescence due to respective changes in extramitochondrial $\mathrm{Ca}^{2+}$ (Fig. 3, insertion). In line with previous reports, addition of $\mathrm{RR}$ to isolated brain mitochondria induced a significant increase in extramitochondrial $\mathrm{Ca}^{2+}$ which was caused by a net $\mathrm{Ca}^{2+}$ release from mitochondria (Fig. 3A) [21]. The subsequent addition of $10 \mu \mathrm{M} \mathrm{Ca}{ }^{2+}$ induced a sustained increase of $\mathrm{Ca}^{2+}$ Green fluorescence, confirming effective inhibition of the $\mathrm{Ca}^{2+}$ uniporter by $\mathrm{RR}$, which is also in accordance with earlier reports [21].
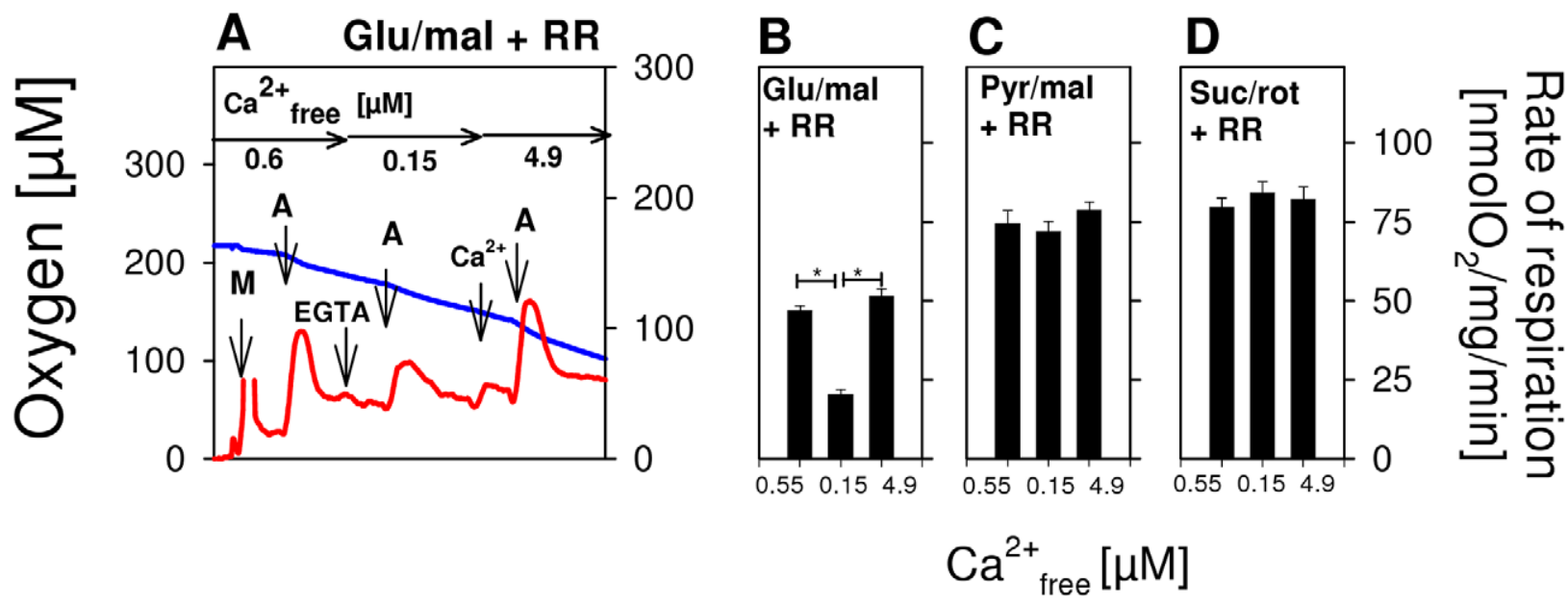

Figure 2. Exclusive and reversible activation of glutamate-dependent respiration by extramitochondrial $\mathrm{Ca}^{2+}$ at low levels of $\mathrm{ADP}$. (A) Isolated rat brain mitochondria $(0.06 \mathrm{mg} / \mathrm{ml})$ were incubated in EGTA-free medium $\left(0.6 \mu \mathrm{M} \mathrm{Ca}^{2+}{ }_{\text {free }}\right)$ with $10 \mathrm{mM}$ glutamate and $2 \mathrm{mM}$ malate as substrates, but in the presence of $250 \mathrm{nM}$ RR. Additions: $M, 0.06 \mathrm{mg} / \mathrm{ml}$ rat brain mitochondria; A, $150 \mu \mathrm{M}$ ADP; EGTA, $100 \mu \mathrm{M}$ EGTA (0.15 $\mu \mathrm{M}$ $\mathrm{Ca}^{2+}$ free); $\mathrm{Ca}^{2+}{ }_{4.91} 4.9 \mu \mathrm{M} \mathrm{Ca}{ }^{2+}$ free. Horizontal arrows indicate the actual $\mathrm{Ca}^{2+}$ free concentration. (B-D). Means of phosphorylating respiration $\pm \mathrm{S}$.E. were calculated as stationary state 3 respiration rate minus state 4 respiration rate from measurements as shown for glutamate and malate in $A$ at defined extramitochondrial $\mathrm{Ca}^{2+}$. Different substrates were used as indicated. ${ }^{*} P<0.01$.

doi:10.1371/journal.pone.0008181.g002 


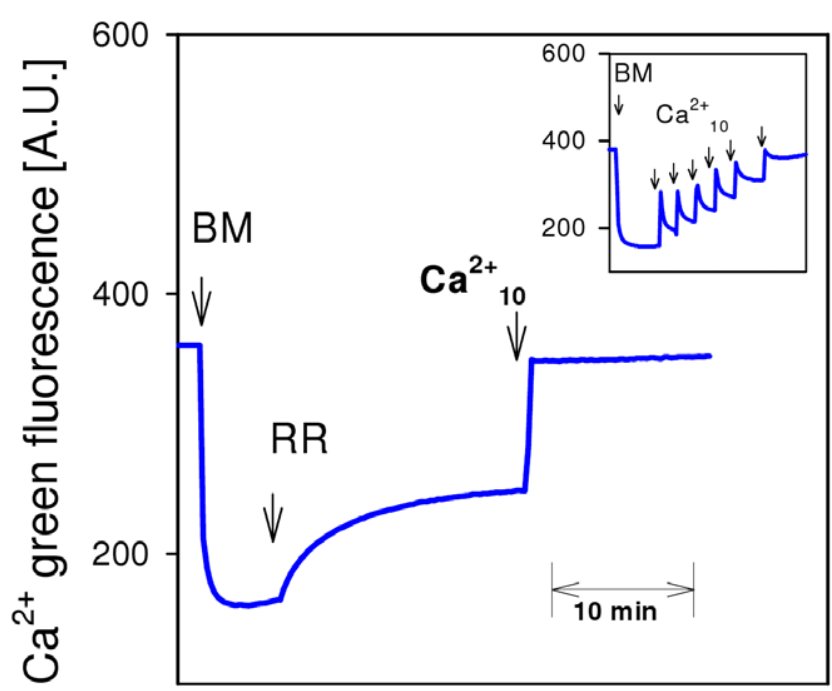

Figure 3. Brain mitochondria do not accumulate, but rather lose, $\mathrm{Ca}^{2+}$ in the presence of ruthenium red. Fluorimetric measurement of extramitochondrial $\mathrm{Ca}^{2+}$ with $\mathrm{Ca}^{2+}$ green. Brain mitochondria were incubated in EGTA-free medium with $10 \mathrm{mM}$ glutamate and $2 \mathrm{mM}$ malate. Additions: $B M, 0.25 \mathrm{mg} / \mathrm{ml}$ brain mitochondria; RR, $250 \mathrm{nM}$ ruthenium red (RR); $\mathrm{Ca}^{2+}{ }_{10}, 10 \mu \mathrm{M} \mathrm{Ca}^{2+}$ free, Insertion: Control experiment without RR demonstrating normal $\mathrm{Ca}^{2+}$ accumulation of brain mitochondria after repeated $\mathrm{Ca}^{2+}$ additions.

doi:10.1371/journal.pone.0008181.g003

In the next series of experiments, we determined the $\mathrm{K}_{\mathrm{M}}$ of mitochondrial $\mathrm{Ca}^{2+}$ uptake via $\mathrm{Ca}^{2+}$ uniporter under conditions used in here. The estimated $\mathrm{K}_{\mathrm{M}}$ of $3.7 \pm 0.9 \mu \mathrm{M} \mathrm{Ca}^{2+}$ free exceeds the $\mathrm{S}_{0.5}$ of $\mathrm{Ca}^{2+}$-activated respiration $\left(360 \mathrm{nM} \mathrm{Ca}^{2+}\right.$ free, Fig. $\left.1 \mathrm{~F}\right)$ about 10 -fold. Such a big difference between $\mathrm{K}_{\mathrm{M}}$ and $\mathrm{S}_{0.5}$ suggests that mitochondrial $\mathrm{Ca}^{2+}$ accumulation cannot take place as long as extramitochondrial $\mathrm{Ca}^{2+}$ remains within the $\mathrm{nM}$ concentration range. To verify this important conclusion, $\mathrm{Ca}^{2+}$ free was monitored directly with Fura-2 under conditions otherwise equivalent to those in respirometric experiments with glutamate/malate and $100 \mu \mathrm{M}$ EGTA-medium (not shown). At $\mathrm{Ca}^{2+}$ free levels up to $1.2 \mu \mathrm{M}$, mitochondrial $\mathrm{Ca}^{2+}$ accumulation was not detectable. Only after further $\mathrm{Ca}^{2+}$ additions did mitochondrial $\mathrm{Ca}^{2+}$ uptake become visible (not shown).

\section{Discussion}

It is widely believed that increased cytosolic $\mathrm{Ca}^{2+}$ exerts a parallel activation of extramitochondrial ATPases and OXPHOS, thereby balancing exactly ATP consumption and production without major changes in ADP concentration $[2,3,6,7,8,10] . \mathrm{Ca}^{2+}$ transport into the mitochondrial matrix and subsequent activation of distinct intramitochondrial dehydrogenases $[2,3,6,7,22,23]$ and $\mathrm{F}_{0} \mathrm{~F}_{1} \mathrm{AT}$ Pase $[8,9]$ are assumed to constitute the regulatory mechanism of mitochondrial respiration and OXPHOS. However, an exclusive activation of OXPHOS by intramitochondrial $\mathrm{Ca}^{2+}$ is questionable in the light of following arguments. (i) Computer modeling of intramitochondrial $\mathrm{Ca}^{2+}$ activation of OXPHOS was unable to simulate the OXPHOS activation in response to physiological changes of work load in vivo [10]. (ii) The low affinity of the mitochondrial $\mathrm{Ca}^{2+}$ uniporter to $\mathrm{Ca}^{2+}$ free $\left(\mathrm{K}_{\mathrm{M}}=3.7 \pm 0.9 \mu \mathrm{M}\right)$ should not allow an effective increase in intramitochondrial $\mathrm{Ca}^{2+}$ effectively under conditions of only slightly elevated $\mathrm{Ca}^{2+}$. Therefore, detectable mitochondrial $\mathrm{Ca}^{2+}$ uptake at nanomolar $\mathrm{Ca}^{2+}$ levels was explained by spatial heterogeneity of cytosolic $\mathrm{Ca}^{2+}$ concentration [24] and/or by a spermine-induced increase in the uniporter's affinity for extramitochondrial $\mathrm{Ca}^{2+}[25,26]$. (iii) Moreover, the relative insensitivities of intramitochondrial dehydrogenases to $\mathrm{Ca}^{2+}\left(\mathrm{S}_{0.5}=0.4-13 \mu \mathrm{M} \mathrm{Ca}^{2+}\right.$ free $)[22,23]$ require significant higher $\mathrm{Ca}^{2+}$ free levels for their activation compared with extramitochondrial $\mathrm{Ca}^{2+}$ activation of state $3_{\text {glu }} / \mathrm{mal}$ and OXPHOS. Thus, the function of mitochondrial $\mathrm{Ca}^{2+}$ uptake and accumulation appears rather to serve as reversible $\mathrm{Ca}^{2+}$ buffer, ensuring intracellular $\mathrm{Ca}^{2+}$ homeostasis, than to regulate state $3_{\mathrm{glu} / \mathrm{mal}}$ and OXPHOS [14].

This study reveals a novel mechanism of extramitochondrial $\mathrm{Ca}^{2+}$ activation of state $3_{\text {glu/mal }}$ and OXPHOS mediated by aralar. This finding is supported by several earlier observations. (i) RR inhibits cardiac function only slightly in vivo [27,28], suggesting that mitochondrial $\mathrm{Ca}^{2+}$ uptake is not obligatory for stimulation of mitochondrial ATP production in vivo. (ii) In contrast, AOA, an inhibitor of MAS, attenuates the respiration of isolated synaptosomes [29] and suppresses the contractile function of the perfused, working heart [30], when glucose or lactate are oxidized. On the other hand, full contractile functionality can be observed if pyruvate is used in the presence of AOA [30].

Since pyruvate formation and aralar function are tightly interconnected in intact cells [11], extramitochondrial $\mathrm{Ca}^{2+}$, beside its regulation of MAS [11-13], also regulates pyruvate formation from glucose or lactate. Since pyruvate is the main substrate of brain mitochondria [31], extramitochondrial $\mathrm{Ca}^{2+}$ is able to adjust the supply of OXPHOS with its main substrates precisely and reversibly, like a physiological "gas pedal", acting in response to distinct, $\mathrm{Ca}^{2+}$-mediated cellular demands.

Taken together, our results imply a new and consistent feature of OXPHOS regulation in brain mitochondria in which the mitochondrial glutamate/aspartate carrier aralar controls mitochondrial substrate supply and OXPHOS according to the extramitochondrial level of $\mathrm{Ca}^{2+}$.

\section{Materials and Methods}

\section{Mitochondria}

Brain mitochondria (containing synaptosomal and nonsynaptosomal fractions) were isolated from 3-4-month-old Wistar WU rats (Charles River Laboratories, Germany) according to the protocol by Kudin et al., which includes permeabilization of synaptosomes with digitonin [32]. Isolation and incubation media did not contain bovine serum albumin (BSA). Before final suspension, the mitochondrial $\mathrm{Ca}^{2+}$ content was routinely diminished by extraction with nitriloacetic acid using the method of Brandt et al. [33]. For some experiments shown in Fig. 1G, mitochondria were isolated without digitonin. These mitochondria were also used to prepare mitoplasts by short term incubation with $1.2 \mathrm{mg}$ digitonin/mg mitochondrial protein similarly as described previously for heart mitoplasts [17]. All research and animal-care procedures were performed according to European guidelines.

\section{Respirometry}

Mitochondrial respiration was measured with a Clark-type oxygen electrode by means of high-resolution respirometry $[34,35]$ using an OROBOROS oxygraph-2k (Oroboros, Innsbruck, Austria) at $30^{\circ} \mathrm{C}$. Respiration of mitochondria ( $0.06 \mathrm{mg}$ protein/ $\mathrm{ml}$ ) was measured in a medium containing $120 \mathrm{mM}$ mannitol, $40 \mathrm{mM}$ MOPS, $5 \mathrm{mM} \mathrm{KH_{2 } \mathrm { PO } _ { 4 } , 6 0 \mathrm { mM } \mathrm { KCl } , 5 \mathrm { mM } \mathrm { MgCl }}$, and either 0 or $100 \mu \mathrm{M}$ EGTA, pH 7.4. $\mathrm{Ca}^{2+}$ free concentrations in the various media were measured with Fura-2 as described below. EGTA-free medium contained $0.6 \mu \mathrm{M} \mathrm{Ca}^{2+}$ free. $100 \mu \mathrm{M}$ EGTA medium contained $0.15 \mu \mathrm{M} \mathrm{Ca}^{2+}$ free. 


\section{$\mathrm{Ca}^{2+}$ accumulation measurements}

$\mathrm{Ca}^{2+}$ accumulation by isolated mitochondria $(0.25 \mathrm{mg}$ protein/ $\mathrm{ml})$ was monitored fluorimetrically in the presence of $0.5 \mu \mathrm{M}$ Calcium Green-5N (Invitrogen) in a medium containing $120 \mathrm{mM}$ mannitol, $40 \mathrm{mM}$ MOPS, $5 \mathrm{mM} \mathrm{KH}_{2} \mathrm{PO}_{4}$ and $60 \mathrm{mM} \mathrm{KGl}$. Measurements were performed in stirred and thermostatted $\left(30^{\circ} \mathrm{C}\right)$ cells using a Carry Eclipse fluorimeter (Varian Deutschland $\mathrm{GmbH})$ as described previously [36]. Excitation and emission wavelengths were set to 506 and $532 \mathrm{~nm}$, respectively.

\section{Measurement of $\mathrm{Ca}^{2+}$ free in EGTA medium}

$\mathrm{Ca}^{2+}$ in EGTA medium was measured fluorimetrically with Fura-2 $(10 \mu \mathrm{M})$ as described previously [37]. The dissociation

\section{References}

1. Chance B, Williams GR (1955) Respiratory enzymes in oxidative phosphorylation. III. The steady state. J Biol Chem 217(1): 409-427.

2. Heineman FW, Balaban RS (1990) Phosphorus-31 nuclear magnetic resonance analysis of transient changes of canine myocardial metabolism in vivo. J Clin Invest 85(3): 843-852.

3. Sharma N, Okere IC, Brunengraber DZ, McElfresh TA, King KL, et al. (2005) Regulation of pyruvate dehydrogenase activity and citric acid cycle intermediates during high cardiac power generation. J Physiol 562(Pt 2): 593-603.

4. Gellerich FN, Schlame M, Bohnensack R, Kunz W (1987) Dynamic compartmentation of adenine nucleotides in the mitochondrial intermembrane space of rat heart mitochondria. Biochim Biophys Acta 890(2): 117-126.

5. Seppet EK, Kaambre T, Sikk P, Tiivel T, Vija H, et al. (2001) Functional complexes of mitochondria with $\mathrm{Ca}, \mathrm{MgATPases}$ of myofibrils and sarcoplasmic reticulum in muscle cells. Biochim Biophys Acta 1504(2-3): 379-395.

6. McCormack JG, Halestrap AP, Denton RM (1990) Role of calcium ions in regulation of mammalian intramitochondrial metabolism. Physiol Rev 70(2): 391-425.

7. Hansford RG, Zorov D (1998) Role of mitochondrial calcium transport in the control of substrate oxidation. Mol Cell Biochem 184(1-2): 359-369.

8. Territo PR, Mootha VK, French SA, Balaban RS (2000) $\mathrm{Ca}(2+)$ activation of heart mitochondrial oxidative phosphorylation: role of the $\mathrm{F}(0) / \mathrm{F}(1)$-ATPase. Am J Physiol Cell Physiol 278(2): C423-35.

9. Das AM (2003) Regulation of the mitochondrial ATP-synthase in health and disease. Mol Genet Metab 79(2): 71-82.

10. Korzeniewski B (2007) Regulation of oxidative phosphorylation through parallel activation. Biophys Chem 129(2-3): 93-110.

11. Satrústegui J, Pardo B, Del Arco A (2007) Mitochondrial transporters as novel targets for intracellular calcium signaling. Physiol Rev 87(1): 29-67.

12. Pardo B, Contreras L, Serrano A, Ramos M, Kobayashi K (2006) Essential role of aralar in the transduction of small $\mathrm{Ca}^{2+}$ signals to neuronal mitochondria. J Biol Chem 281(2): 1039-1047.

13. Palmieri L, Pardo B, Lasorsa FM, del Arco A, Kobayashi K (2001) Citrin and aralarl are $\mathrm{Ca}(2+)$-stimulated aspartate/glutamate transporters in mitochondria. EMBO J 20(18): 5060-5069.

14. Rizzuto R, Pozzan T (2006) Microdomains of intracellular $\mathrm{Ca}^{2+}$ molecular determinants and functional consequences. Physiol Rev 86(1): 369-408.

15. Moore G (1971) Specific inhibition of mitochondrial Ca++ transport by ruthenium red. Biochem Biophys Res Commun 42(2): 298-305.

16. Schnaitman C, Greenawalt JW (1968) Enzymatic properties of the inner and outer membranes of rat liver mitochondria. 38(1): 158-175.

17. Gellerich FN, Khuchua ZA, Kuznetsov AV (1993) Influence of the mitochondrial outer membrane and the binding of creatine kinase to the mitochondrial inner membrane on the compartmentation of adenine nucleotides in the intermembrane space of rat heart mitochondria. Biochim Biophys Acta 1140(3): 327-334.

18. Gellerich FN, Laterveer FD, Korzeniewski B, Zierz S, Nicolay K (1998) Dextran strongly increases the Michaelis constants of oxidative phosphorylation and of mitochondrial creatine kinase in heart mitochondria. Eur J Biochem 254(1): $172-180$.

19. Nicolli A, Basso E, Petronilli V, Wenger RM, Bernardi P (1996) Interactions of cyclophilin with the mitochondrial inner membrane and regulation of the permeability transition pore, and cyclosporin A-sensitive channel. J Biol Chem 271(12): 2185-2192. constant $\left(\mathrm{K}_{\mathrm{d}}\right)$ of the $\mathrm{Ca}^{2+}$-Fura-2 complex was determined experimentally under these conditions and was found to be $0.3 \mu \mathrm{M}$, which was similar to that found in a previous study [37].

\section{Protein determination}

Mitochondrial protein concentrations were determined by the bicinchoninic acid assay [38], with BSA used as standard.

\section{Author Contributions}

Conceived and designed the experiments: FNG SV ES. Performed the experiments: ZG OA DJ. Analyzed the data: ZG ES. Wrote the paper: FNG FS. Conception: SV. Design and interpretation of new experiments: SV.

20. LaNoue KF, Tischler ME (1974) Electrogenic characteristics of the mitochondrial glutamate-aspartate antiporter. J Biol Chem 249(23): 7522-75228.

21. Rossi CS, Vasington FD, Carafoli E (1973) The effect of ruthenium red on the uptake and release of $\mathrm{Ca} 2+$ by mitochondria. Biochem Biophys Res Commun 50(3): 846-852.

22. Rutter GA, Denton RM (1988) Regulation of NAD+-linked isocitrate dehydrogenase and 2-oxoglutarate dehydrogenase by $\mathrm{Ca} 2+$ ions within toluene-permeabilized rat heart mitochondria. Interactions with regulation by adenine nucleotides and NADH/NAD+ ratios. Biochem J 252(1): 181-189.

23. Rutter GA, Midgley PJ, Denton RM (1989) Regulation of the pyruvate dehydrogenase complex by $\mathrm{Ca}^{2+}$ within toluene-permeabilized heart mitochondria. Biochim Biophys Acta 1014(3): 263-270.

24. Rizzuto R, Pozzan T (2006) Microdomains of intracellular $\mathrm{Ca}^{2+}$ molecular determinants and functional consequences. Physiol Rev 86(1): 369-408.

25. McCormack JG (1989) Effects of spermine on mitochondrial Ca2+ transport and the ranges of extramitochondrial $\mathrm{Ca} 2+$ to which the matrix $\mathrm{Ca} 2+$-sensitive dehydrogenases respond. Biochem J 264(1): 167-174.

26. Lenzen S, Münster W, Rustenbeck I (1992) Dual effect of spermine on mitochondrial Ca2+ transport. Biochem J 286(Pt 2): 597-602.

27. Unitt JF, McCormack JG, Reid D, MacLachlan LK, England PJ (1989) Direct evidence for a role of intramitochondrial $\mathrm{Ca}^{2+}$ in the regulation of oxidative phosphorylation in the stimulated rat heart. Studies using $31 \mathrm{P}$ n.m.r. and ruthenium red. Biochem J 262(1): 293-301.

28. García-Rivas Gde J, Carvajal K, Correa F, Zazueta C (2006) Ru360, a specific mitochondrial calcium uptake inhibitor, improves cardiac post-ischaemic functional recovery in rats in vivo. Br J Pharmacol 149(7): 829-837.

29. Kauppinen RA, Sihra TS, Nicholls DG (1987) Aminooxyacetic acid inhibits the malate-aspartate shuttle in isolated nerve terminals and prevents the mitochondria from utilizing glycolytic substrates. Biochim Biophys Acta 930(2): 173-178.

30. Bünger R, Glanert S, Sommer O, Gerlach E (1980) Inhibition by (aminooxy)acetate of the malate-aspartate cycle in the isolated working guinea pig heart. Hoppe Seylers Z Physiol Chem 361(6): 907-914.

31. Brown GK, Otero LJ, LeGris M, Brown RM (1994) Pyruvate dehydrogenase deficiency MJ Med Genet. 31(11): 875-879.

32. Kudin AP, Bimpong-Buta NY, Vielhaber S, Elger CE, Kunz WS (2004) Characterization of superoxide-producing sites in isolated brain mitochondria. J Biol Chem 279(6): 4127-4135.

33. Johnston JG, Brand MD (1986) Some properties of rat liver mitochondria with low $\mathrm{Ca}^{2+}$ content. Biochem Soc Trans 14(4): 1182-1185.

34. Kuznetsov AV, Veksler V, Gellerich FN, Saks V, Margreiter R, et al. (2008) Analysis of mitochondrial function in situ in permeabilized muscle fibers, tissues and cells. Nat Protoc 3(6): 965-976.

35. Gnaiger E (2001) Bioenergetics at low oxygen: dependence of respiration and phosphorylation on oxygen and adenosine diphosphate supply. Resp Phys 128(3): 277-297.

36. Gizatullina ZZ, Ghen Y, Zierz S, Gellerich FN (2005) Effects of extramitochondrial ADP on permeability transition of mouse liver mitochondria. Biochim Biophys Acta 1706(1-2): 98-104.

37. Groden DL, Guan Z, Stokes BT (1991) Determination of Fura-2 dissociation constants following adjustment of the apparent Ca-EGTA association constant for temperature and ionic strength. Cell Calcium 12(4): 279-287.

38. Wiechelman KJ, Braun RD, Fitzpatrick JD (1988) Investigation of the bicinchoninic acid protein assay: identification of the groups responsible for color formation. Anal Biochem 175(1): 231-237. 